\title{
Ensino de História, aprendizagem significativa e a atuação do professor: desafios do tempo presente
} Teaching History, Meaningful Learning and the Role of the Teacher: Challenges of the Present Time

\author{
Naicon Souza Brinco* \\ Maria Aparecida da Silva Cabral ${ }^{\star *}$
}

\section{RESUMO}

O presente artigo discute o impacto e as potencialidades do fenômeno da expansão do ciberespaço e das mídias digitais no ensino de História na educação básica, a partir de uma pesquisa realizada em duas turmas do sexto ano do ensino fundamental, no Estado do Rio de Janeiro. Objetiva-se tecer uma reflexão acerca da construção da aula de História pelo professor-autor em diálogo à educação intercultural, híbrida, no contexto das novas mídias, valorizando a potencialidade do uso da narrativa na construção teórico-metodológica da aula. Considera-se o fenômeno da expansão da cibercultura no entendimento das formas narrativas que os jovens têm contato em suas vivências e as mediadas pelo professor no espaço escolar, nos processos de ensino e aprendizagem da História.

Palavras-chave: ensino de História; saberes e práticas no espaço escolar; mídias digitais.

\section{ABSTRACT}

This article discusses the impact and potentialities of the phenomenon of the expansion of cyberspace and digital media in the teaching of History of basic education from a case study conducted with two classes of the sixth year of elementary school, on State of Rio de Janeiro. The objective is to weave a reflection about the construction of the History class by the teacher-author in dialogue to intercultural, hybrid education, in the context of new media, valuing the potentiality of the use of narrative in the theoreticalmethodological construction of the class. It is considered the phenomenon of the expansion of cyberculture in the understanding of narrative forms that young people have contact in their experiences and those mediated by the teacher in the school space, in the processes of teaching and learning History.

Keywords: teaching of History; knowledge and practices in the school space; digital media.

\footnotetext{
* Universidade do Estado do Rio de Janeiro (UERJ), Rio de Janeiro, RJ, Brasil. naiconro@hotmail.com

** Universidade do Estado do Rio de Janeiro (UERJ), Rio de Janeiro, RJ, Brasil. cidacabral4567@ gmail.com
} 
A discussão sobre aprendizagem na educação brasileira, certamente, é um tema que envolve muitos desafios. Nos últimos anos, tem sido não somente objeto de atenção das autoridades educacionais - responsáveis pela execução de políticas públicas - e das universidades - que formam os profissionais atuantes no campo educacional - mas também dos professores, que lidam diretamente com os processos formativos de crianças, adolescentes e jovens em situação de escolarização. Tais questões se fazem cada vez mais recorrentes em investigações sobre o ensino de História no Brasil, chamando a atenção de historiadores que se voltam para a compreensão das concepções e práticas que dão forma ao saber histórico escolar.

É nesse contexto de valorização de pesquisas que ambicionam desvendar práticas construídas por professores e estudantes no espaço da sala de aula, com vistas à realização da aprendizagem em História, que elaboramos uma investigação no âmbito do Mestrado Profissional em Ensino de História Profhistória UERJ, entre 2018 e 2020. ${ }^{1}$ Focalizamos temas e questões relacionadas à prática dos professores de História, com o objetivo de protagonizar junto aos estudantes do sexto ano do ensino fundamental experiências significativas na construção do conhecimento histórico, em diálogo com referenciais teórico-metodológicos do campo do ensino de História.

Considerando que o fenômeno das mídias digitais tem impactado os formatos de ensino das disciplinas escolares e as maneiras de aprender, almejamos apresentar algumas reflexões em torno dos usos de novas mídias em sala de aula e como estas podem contribuir na construção de narrativas históricas. Diante disso, indagamos: Quais desafios estão postos aos professores de História, na contemporaneidade, na tarefa de ensinar esse conhecimento a estudantes da educação básica? Como criar situações de ensino que proporcionem uma aprendizagem significativa a estudantes que muitas vezes não veem sentido nesse conhecimento? De que modo os usos da tecnologia podem contribuir nas aulas de História?

Vários pesquisadores têm defendido a riqueza do espaço escolar e, principalmente, da sala de aula, na proposição de experiências que problematizem o social e proporcionem socializações, constituição de identidades individuais e coletivas, de subjetividades, entre outras. Especificamente, a sala de aula tem o potencial de ser um espaço onde todos podem aprender (professores e estudantes), "formando-se no contexto cultural, histórico e social no qual essa 
relação se institui" (MADDALENA; ROSSINI; SANTOS, 2018, p. 98), em uma construção individual e coletiva de autoria do professor (MATTOS, 2006).

Ilmar Mattos (2006) nos ensina que a aula é resultado de várias operações construídas pelo professor de História, como algo em constante movimento, não inerte, que se inscreve de forma efêmera entre professor e aluno - possuidores de um conjunto de saberes simbólicos comuns que possibilitam o desenvolvimento do processo de comunicação. Na perspectiva desse autor, o estudante é o leitor que apropriar-se-á, ressignificará e produzirá novos sentidos ao deslocar-se entre a leitura da aula e suas leituras de mundo (MATTOS, 2006). Enquanto escritores de História desenvolvem na produção do texto o trabalho narrativo de um amplo processo metodológico de pesquisa, verificação, seleção e análise do discurso das fontes (BARROS, 2011), o professor de História constrói a aula como resultante de um extenso processo metodológico de seleção e leitura da produção historiográfica, das fontes e dos conceitos históricos a serem operados no processo de ensino e da relação professor-aluno em seus diferentes saberes e experiências de vida (MATTOS, 2006).

Importa destacar nessas ideias que em uma aula de História, é imprescindível no decorrer do processo de aprendizagem a participação dos discentes com os saberes e conhecimentos acerca do passado que possuem, fruto de suas trajetórias (FERREIRA, 2018). Esse posicionamento não implica anular as diferenças entre o papel do professor e dos estudantes, pois há, por parte do adulto, a responsabilidade de proteção e bem-estar dos jovens alunos, constituindo a posição de autoridade do professor como "potencializador do processo de ensino-aprendizagem" e não "exercício arbitrário do poder adulto" (LEITE, 2009, p. 123).

Consideramos que na construção do conhecimento histórico escolar a aprendizagem dos conceitos científicos é mediada pelo professor, sob a base de conceitos genéricos apreendidos pelos jovens em suas vivências - estas mediadas pela família e contexto social em que vivem (VYGOTSKY, 2008). Portanto, uma aula de História dialoga com a vivência dos estudantes enquanto transita pelo conhecimento historiográfico e os saberes da prática do professor, nas escolhas metodológicas. Potencializa a aprendizagem ao valorizar e reconhecer cada sujeito envolvido e ao combater "todas as formas de silenciamento, invisibilização e/ou subalternização de determinados sujeitos socioculturais" (CANDAU, 2009, p. 43). 


\section{EFEITOS DO PRESENTISMO NO ENSINO DE HISTÓRIA}

Nas últimas décadas a educação brasileira tem passado por inúmeras reformas curriculares impulsionadas por um movimento que advém da nova ordem mundial, que se faz com a imposição de um modelo econômico, resultado da lógica de mercado. No caso dos currículos brasileiros, verificamos uma intensa disputa a respeito dos significados sociais e políticos quanto à função das disciplinas escolares, ao papel que estas devem desempenhar na formação de sujeitos e, ainda, a um redirecionamento das finalidades educativas.

Um dos resultados desse modo de pensar e organizar os currículos se expressa na construção de projetos pedagógicos contemporâneos que deslocam a centralidade dos conceitos de formação e desenvolvimento para a ideia de flexibilidade - relacionada à capacidade de reação a uma condição de contínuo movimento e hiperaceleração a um destino não definido (TURIN, 2018). Considerando o histórico da instituição escolar na manutenção da ordem social e atendimento das demandas do capital (MARRACH, 2009), vincula-se a este fenômeno o imediatismo que caracteriza os tempos do mercado (HARTOG, 2013). Após a consolidação do rompimento com o modelo fordista na década de 1980, há o aumento exponencial do uso do conceito de flexibilidade no mundo do trabalho, gradualmente expandido para a esfera cultural, alcançando nas reformas do Ensino Médio e na Base Nacional Comum Curricular (BNCC) o campo educacional (TURIN, 2018).

Em paralelo à flexibilidade são identificados a expansão dos conceitos de eficiência e atualização, que juntos formam uma rede semântica própria que compreende o Estado como instância de gerenciamento e os representantes eleitos como gestores responsáveis por atender com rapidez às demandas do mercado internacional (TURIN, 2018). Este fenômeno reforça a experiência de presente perpétuo, no qual o transitório é uma permanência que se expande e esvazia o passado (HARTOG, 2013) na celeridade de torná-lo obsoleto, pois o Estado e os sujeitos, para responder aos interesses do mercado internacional, devem, nesta perspectiva, estar em constante atualização.

Percebemos a relação temporal dos sujeitos, individuais ou coletivos, marcada pela aceleração e mobilidade, evidenciados na expansão do conceito de flexibilidade, como um fenômeno relacionado à hipótese do presentismo (HARTOG, 2013). Ao operar as categorias de análise de espaço de experiência e horizonte de expectativas (KOSELLECK, 2006), Hartog propôs a hipótese 
dos Regimes de Historicidades como instrumento analítico da experimentação do tempo por indivíduos e coletividades (HARTOG, 2013).

Segundo Koselleck (2006), o espaço de experiência é o passado atual, incorporado, lembrado, mesmo que não vivido. Abrange não só o conhecimento racional, como o comportamento inconsciente. O passado salvaguardado pelas histórias narradas entre as gerações que se aglomeram para formar um todo. Assume um caráter espacial, em que muitos estratos de tempo estão presentes de maneira simultânea, sem um antes e um depois.

O horizonte de expectativa é o futuro presente, o ainda-não, o futuro lembrado enquanto previsão. Este também abrange o comportamento inconsciente, mas pode se manifestar pela análise racional ou visão perspectiva. Inversamente ao espaço de experiência, estende-se por dias, anos e séculos. Decompõe-se em uma infinidade de momentos temporais, futuros trazidos ao presente pela expectativa. No entanto, os acontecimentos que ocorrerão com o prognóstico do horizonte de expectativas não são determinados - apesar de se relacionarem - pelo espaço de experiência, afastando-se de uma História determinista (KOSELLECK, 2006).

Tais categorias históricas entrelaçam passado e futuro, pois o tempo histórico é uma grandeza que se modifica e pode ser identificada com a variável entre expectativa e experiência (KOSELLECK, 2006). Ao utilizar esta ferramenta heurística, Hartog (2013) identificou características específicas na forma com a qual o tempo é experimentado em diferentes sociedades e temporalidades. Denominou como presentismo a experimentação caracterizada pela hipertrofia do presente, que ocupa quase por completo o espaço de experiência, avança sobre o horizonte de expectativas e apresenta o resultado de um "presente onipresente, onipotente que se impõe como único horizonte possível e que valoriza só o imediatismo" (HARTOG, 2013, p. 14).

Caso a instituição escolar possua a finalidade de atender demandas do mercado e adequar-se a seus tempos hiperacelerados, pode vir a reproduzir subordinação e dominação, principalmente em sociedades com desigualdades de meios para realizar escolhas (KALLÁS, 2017, p. 152). Pensar a escrita ou a aula de História privilegiando a utilidade instrumental imediata, na busca de legitimação social, pode minar interna e externamente a produção de conhecimento em suas bases conceituais (TURIN, 2018). Ser direcionado pelo mercado significa responder a seus tempos no atendimento das demandas e incorporação do vocabulário em avaliações de pesquisa, selos de qualidade e 
eficiência - que priorizam a flexibilidade, a celeridade e o caráter quantitativo. Porém, ao assumir formas não necessariamente econômicas, tem o potencial de produzir resistência e hegemonia alternativa (KALLÁS, 2017, p. 152).

Diante desse cenário marcado pela aceleração do tempo que impõe pragmatismo ao campo do conhecimento, o que pode o ensino de História? Qual a tarefa do professor nesse contexto?

O ensino de História, ao ampliar o espaço de experiência para além do presente vivido, tem o potencial de assumir uma forma ligada à cidadania e constituição de identidades, integrada à concepção de escola que resiste à subordinação dos interesses do mercado. O professor da Educação Básica, ao lançar o olhar para a atuação do sujeito na sociedade (CAIMI; OLIVEIRA, 2012), tem por objetivo evitar que se consolide um modelo de cidadania que exclui a realidade local ao verter a concepção das elites do Estado do que é ser cidadão em regra geral. Promove a percepção dos estudantes de se enxergarem sujeitos históricos, capazes de realizarem escolhas e promoverem mudanças.

Afastar o processo de ensino de História da mobilização das fontes e de conceitos, aproximando a significação de educação à de mercadoria, ao atender às demandas de mercado, pode vir a pôr o lucro como principal objetivo (FERREIRA, 2018). Portanto, a legitimação da disciplina histórica que preserve a autonomia na produção do conhecimento se dá na própria defesa da autonomia da universidade (TURIN, 2018) e do professor da Educação Básica enquanto autor da aula (MATTOS, 2006), o que não significa ignorar as demandas sociais ou afastamento da universidade e das escolas como ilhas separadas de conhecimento.

A expansão dos debates sobre a História Pública, na Educação Superior e na Educação Básica abordados por Ferreira (2018) - que não se limitam à ideia de divulgação científica ou transposição didática, pois buscam a valorização do diálogo na mediação didática entre os saberes dos professores, a produção historiográfica, a vivência sociocultural dos estudantes e os passados circulantes - indicam o movimento da disciplina numa desejável democratização da universidade.

Se por um lado há a pressão exercida pelos tempos do mercado nos projetos pedagógicos e nas políticas educacionais do Estado, de outro há uma experimentação do tempo mediada no ciberespaço por parte dos estudantes, com um grande volume de informações - forma de comunicação caracterizada pela efemeri- 
dade (BENJAMIN, 2012) - que privilegia a noção temporal de simultaneidade, em detrimento do sentido de permanência (MIRANDA, 2012).

\section{POTENCIALIDADES DA NARRATIVA NO ENSINO-APRENDIZAGEM DE HISTÓRIA EM CONTEXTO DA CIBERCULTURA}

As narrativas expressam de algum modo a experiência que temos com nossa cultura e a compreensão das maneiras como são feitas contam também um pouco como os jovens narradores se situam no contexto de suas histórias (FERNANDES, 2019). Ao narrar, os jovens intercambiam suas experiências, sendo relatadas de pessoa para pessoa. Narração implica memória, construção de imagens acerca do passado. Trata-se da "impressão deixada pelos acontecimentos e que permanece fixada no espírito” (RICOEUR, 1994, p. 27). As ficções construídas pelos jovens auxiliam a revelar suas relações sociais e percepções do mundo, além de oportunizar que liguem suas próprias histórias às narrativas por nós, professores, apresentadas.

Sob a perspectiva que o desenvolvimento cognitivo dos estudantes acontece por meio de suas experiências socioculturais e instrumentos linguísticos (VYGOTSKY, 2008), considera-se a mediação pela narrativa a principal forma de representar as ações humanas e conhecer o mundo (FREITAS, 2019). O que vem a corresponder ao conceito de História proposto por Bloch (2002), de ser a ciência que estuda os seres humanos e suas ações no tempo.

Fernandes (2019, p. 95) afirma que "o contar histórias faz parte de nossa humanidade e nos encanta desde sempre [...] que contar histórias faz parte de nós”. Assim sendo, os sujeitos são históricos, marcados por uma cultura, ao criar e recriar a realidade social construindo ideias e narrativas. Sobre essa questão, tal autora destaca que:

Houve momentos históricos em que as histórias com as quais as crianças se envolviam eram as que circulavam oralmente na comunidade, enraizadas na experiência de tipo rural. As narrativas, então, ainda não levavam em conta as especificidades infantis e o que se contava e ouvia eram os "causos" verídicos que, enriquecidos com a máxima de "quem conta um conto aumenta um ponto", prendiam a atenção de adultos e crianças. Com o surgimento do sentimento de infância, esses contos populares são convertidos em matéria apropriada para os pequenos ouvintes, passando a despertar sua preferência. A voz do contador, ou 
a técnica do contar, correspondia à preferência. Mais adiante, a literatura infantil impressa passa a disputar com a oralidade a preferência das crianças pelas histórias. Podiam-se ouvir histórias com ou sem o apoio do livro, bem como era possível ler as histórias e a preferência, agora, estava ligada não apenas ao estilo do contar, mas à materialidade do objeto livro dirigido à infância. Hoje, as histórias também são contadas pelas diferentes mídias e presentes nas diferentes telas e continuam satisfazendo as necessidades de fantasia da criança por intermédio de outras linguagens e de outras técnicas. A preferência pelas histórias, hoje, foi ampliada relativamente a esse aumento de possibilidades de acesso, de modos de fruição e do próprio conteúdo das histórias. Um modo não substitui ou anula o outro, mas diversifica a preferência das crianças. (FERNANDES, 2019, p. 89)

A narrativa possui um caráter temporal que organiza uma sucessão de eventos e ações (MADDALENA; ROSSINI; SANTOS, 2018). Segundo Ricoeur (1994), é engendrada pelo agenciamento de fatos. Têm-se considerado que operá-la em sala de aula auxilia no aprofundamento da temporalidade, por meio da representação das ações, na qual a disposição dos fatos possui as características de completude, totalidade e extensão apropriada.

A completude emerge na apresentação de uma sequência de episódios ligados pela intriga. Visto que os episódios não ocorrem ao acaso, mas contém uma sequência de ações, os estudantes podem identificar a causalidade. No entanto, a fim de evitar a concepção fatalista, ressalta-se que a causalidade está relacionada à probabilidade imaginária: os eventos poderiam trilhar caminhos diferentes de acordo com acontecimentos variáveis, estando diretamente relacionados às condições propiciadas por acontecimentos anteriores e/ou simultâneos (RICOEUR, 1994).

A totalidade é caracterizada por ter um começo, um meio e um fim: o começo não tem necessidade de um antecedente e o fim de uma sucessão. $\mathrm{O}$ todo é o efeito da ordenação baseada nas necessidades e probabilidades (RICOEUR, 1994). Em atividades com os estudantes, ao traçarmos uma linha do tempo com acontecimentos sob uma temática, a princípio poderíamos estar nos aproximando de uma cronologia linear. No entanto, ao tratarmos o todo, enquanto ordenação construída pelo autor, há a possibilidade de transformar uma sucessão de eventos em uma totalidade significante.

A extensão apropriada é temporal: é o tempo da inversão "entre uma série de eventos encadeados segundo o verossímil ou o necessário" (RICOEUR, 1994, p. 66). A mudança de sorte na vida dos seres humanos ou das classes 
sociais - se forem estes os personagens - constituem tais inversões na tessitura da intriga narrativa. Sorte não no sentido do acaso, mas aproxima-se da felicidade ou infelicidade dos personagens. Nesta perspectiva, a narrativa deve ser construída de forma não muito curta para evitar tornar-se vazia, sem acontecimentos e personagens que a preencham. Se demasiadamente longas anulam o impacto e a percepção das mudanças e rupturas.

Ao tratar o todo, enquanto ordenação, há possibilidade de transformar uma sucessão de eventos em uma totalidade significante, não fatalista, no uso da probabilidade imaginária (RICOEUR, 1994, p. 104). Com esta operação, a intriga pode ser traduzida em um assunto ou tema. $\mathrm{O}$ uso da narrativa pelo professor, que contemple as características de completude, totalidade e extensão apropriada, distancia o ensino de História da linearidade baseada na cronologia. Além de possibilitar a abordagem - de forma concomitante ao conteúdo da experiência histórica - de conceitos históricos, dando-lhe vida nas ações dos personagens ao encontrar o universal dentro do singular (RICOEUR, 1994) e formular questões junto aos estudantes sobre como o presente é construído no tempo (DOSSE, 2012, p. 119). O processo de aprendizagem torna-se significativo à medida que há a problematização das ações humanas no mundo (FREIRE, 1987).

Compreendemos a atuação do professor como mediador na aprendizagem dos conceitos e conteúdos históricos, por isso, na pesquisa que desenvolvemos, nos movimentamos entre as vivências dos discentes e o conhecimento de natureza historiográfica. Ambos mediados pela narrativa na forma de representar e se relacionar com o mundo, cada qual nas linguagens que lhe são próprias. Porém, que narrativas estariam os jovens hoje tendo contato fora do espaço escolar, criando e recriando?

Cumpre-nos pensar se as crianças não têm mais histórias para contar ou se as contam em outras configurações que nem sempre conseguimos perceber, em novos formatos. [...] Em quase todos os cantos desse nosso planeta não é mais possível pensar numa dimensão narrativa que não esteja mediada pela linguagem da TV, do computador e das diferentes mídias - agora mais recentemente até mesmo pelo YouTube - que trazem mudanças constantes em nossos modos de ver e pensar o mundo. (FERNANDES, 2019, p. 102)

Entre os diferentes formatos de narrativa que os jovens têm contato em seus cotidianos, as encontradas no ciberespaço podem ser caracterizadas, devido à velocidade e efemeridade das informações, pela fragmentação, ou seja, 
narrativas quebradas sempre a recomeçar (FERNANDES, 2019). Ao operar sob a perspectiva de Ricoeur (1994), as narrativas fragmentadas são episódios isolados, um após o outro, que perdem seu fio tecido na teia de intriga. Estas histórias variantes, possuem muitas possiblidades e a qualquer momento o fim pode ser outro (FERNANDES, 2019).

Esse não determinismo ocorre não pela probabilística e, sim, pela casualidade. Ao desconectar o fim da história de seu todo, perde o princípio da totalidade e, desta forma, descaracteriza o caráter temporal da narrativa (RICOEUR, 1994). O funcionamento de canais infantis do YouTube usa a forma narrativa própria das crianças, de mudar e inventar, para atingir um mercado que visa o lucro, o marketing e o aumento do número de curtidas, distanciando-se do sentido original da brincadeira para diversão (FERNANDES, 2019).

O conceito abordado por Ricoeur (1994) da causalidade a partir da probabilidade imaginária em diálogo com a contribuição de Koselleck (2006) das categorias espaço de experiência e horizonte de expectativas consolida o rompimento com uma História fatalista ou determinista na sala de aula, enquanto arcabouço teórico da metodologia de ensino.

Koselleck (2006), ao utilizar as categorias de análise histórica de espaço de experiência e horizonte de expectativa no estudo da Idade Média Europeia, identificou que o horizonte de expectativa se encontrava no pós-vida. No espaço de experiência eram formadas as soluções para a vida prática. O comportamento humano buscava uma vida melhor após a morte. Socialmente, tais fenômenos refletem em dados que demonstram não haver grandes rupturas tecnológicas ou na forma de se viver durante o tempo de uma vida: as expectativas eram alimentadas pelas experiências passadas entre as gerações. $\mathrm{O}$ surgimento da ideia de progresso, na Idade Moderna, torna a História conceitualizada como uma unidade contínua, a flecha do tempo, a certeza de que o futuro seria melhor, sendo esse "melhor" promovido por mudanças no plano terreno. No campo da sociopolítica, esta relação temporal resultou na hierarquização das sociedades e saberes, classificando povos mais e menos evoluídos. Tornou-se inviável ensinar a História como exemplo a ser mantido.

Portanto, fundamentado nas análises de Koselleck (2006), consideramos que a forma dos sujeitos e das sociedades se relacionarem com o tempo e agirem sobre ele é associada à dinâmica entre o espaço de experiência e horizonte de expectativas. Promover a aprendizagem em História a partir da construção de narrativas que incorporam experiências passadas (BENJAMIN, 2012) 
tem por objetivo expandir o espaço de experiência para além do presente vivido, tensionar o horizonte de expectativa (KOSELLECK, 2006), romper com o caráter de simultaneidade privilegiado pela cibercultura em seu modo de comunicação marcado pela efemeridade das informações (MIRANDA, 2012) e escapar da hipertrofia do presente (HARTOG, 2013).

\section{CIBERCULTURA, MÍDIAS DIGITAIS E O ENSINO DE HISTÓRIA}

A reflexão acerca do impacto da cibercultura no contexto educacional surge a partir de diversos questionamentos relacionados à nossa prática docente em História na Educação Básica da Rede Pública, no Estado do Rio de Janeiro. Esta pôde ser aprimorada, tornando-se objeto de análise no curso de mestrado em Ensino de História. No decorrer dos anos, observamos a intensificação da utilização de aparelhos de acesso ao ciberespaço nas mais diversas faixas etárias. E a inclusão de um vocabulário próprio da cibercultura, na fala dos estudantes: termos como postar, compartilhar, twittar, curtir, dar um google, ressignificados enquanto práticas culturais em ações realizadas nos espaços digitais (SANTOS; WEBER, 2014).

As novas tecnologias de comunicação do segundo milênio diminuíram os custos de produção e distribuição de informações. Este fenômeno forma um processo no qual, de um lado, as grandes corporações aceleram o fluxo de conteúdo e oportunizam seus lucros e, de outro, os usuários finais têm acesso a diferentes tecnologias que possibilitam a produção de conteúdo e interação com outros sujeitos - o que os torna ativos, migratórios, conectados socialmente e promove o desejo de fazer-se ouvir nos espaços públicos (JENKINS, 2009).

Nesse cenário, o ciberespaço tem ocupado um lugar de destaque como fonte de informação. O YouTube, por exemplo, repositório de vídeo e site com maior número de acessos da internet, causou uma revolução na forma de produção e compartilhamento de imagens (SANTOS; WEBER, 2014, p. 17). Segundo dados divulgados pelo próprio site, ${ }^{2}$ em 2018 houve 1.9 bilhões de acessos mensais no mundo. Os vídeos nele hospedados são compartilhados em diversas redes sociais, como WhatsApp, Facebook e Twitter expandindo ainda mais seu alcance.

Segundo Candau (2009) é fundamental, para os processos de aprendizagem, a dimensão cultural a qual os alunos estão inseridos, de forma a torná-la mais significativa. Atribuir significados é também produzir cultura, pois por meio da 
análise do sentido que os jovens dão ao conteúdo curricular em suas narrativas pode-se perceber os impasses e o processo de criação na aprendizagem.

Miriam Leite, defende que a "lógica narrativa se altera com o mundo eletrônico da comunicação, seja com o Hipertexto ${ }^{3}$ ou via controle remoto da programação televisiva" (LEITE, 2009, p. 127). A sociedade da Era Google, ${ }^{4}$ portanto, foi modificada pela web, tendo ainda como resultante, uma nova esfera global pública. Na qual habitam autores de blogs, páginas, perfis, canais, ou seja, novos atores que fazem uso do passado em seus discursos, num espaço onde todos podem falar e autoproclamar-se especialistas (LUCCHESI, 2014).

Cultura letrada e visual se mesclam de forma híbrida, pois a inserção de narrativa audiovisual não pressupõe a exclusão da escrita, mas convoca a reflexão da necessidade da experimentação da linguagem da imagem no espaço escolar, já que a diferenciação entre a cultura letrada e a cultura visual expõe a distância entre os adultos e as crianças, para as quais o contato com as narrativas não têm no texto escrito uma centralidade (FERNANDES, 2019).

As imagens dessas novas mídias digitais não são apenas uma complementação do texto escrito, mas um outro texto que tem forte presença na formação dos jovens na atualidade (FERNANDES, 2019). A Hipermídia não depende do espaço-tempo de sua emissão/criação/postagem, pois hibridiza sons, imagens e textos cheios de informação com características multidimensionais, (re)construídas de forma dinâmica de acordo com a navegação de cada sujeito - sendo possível transitar por todos os processadores digitais do mundo ao serem transformados em códigos binários (0 e 1), a linguagem da máquina (MADDALENA; ROSSINI; SANTOS, 2018).

Os textos escritos e a linguagem verbal foram privilegiadas na web 1.0, na qual era necessário conhecimento especializado por parte dos usuários. A web 2.0 apresenta interfaces colaborativas e softwares sociais livres, de uso gratuito, com troca de mensagens em tempo real (MADDALENA; ROSSINI; SANTOS, 2018). As chamadas "redes sociais" (Facebook, YouTube, Instagram, Twitter, WhatsApp) integram este movimento, ao emergir como ambientes virtuais que permitem aos usuários construir páginas e compartilhar conteúdo de forma simples e interativa.

Os endereços eletrônicos do ciberespaço representados na Figura 1 e Figura 2 são selecionados para exemplificar o fenômeno por (i) serem identificados como redes sociais utilizadas pelos estudantes e (ii) serem ambientes virtuais que apresentam interface colaborativa, troca de mensagens em tempo real e não dependerem de conhecimento especializado para utilização. 
Figura 1 - Página incial do Facebook

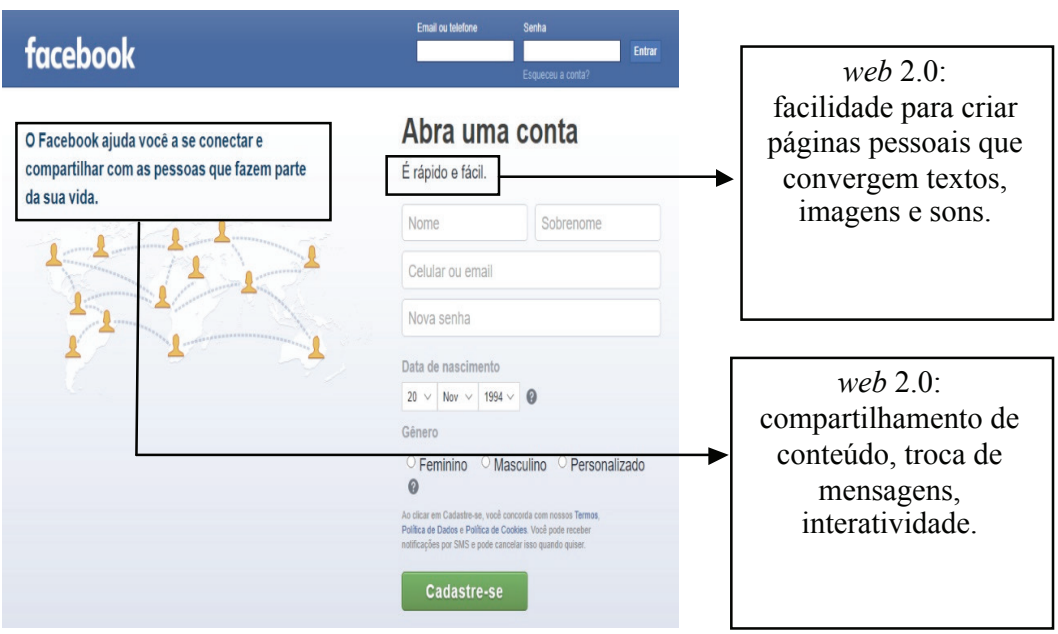

Fonte: Facebook. Disponível em: www.facebook.com; Acesso em: 27 mar. 2020.

Figura 2 - YoTube: Site de compartilhamento de vídeos

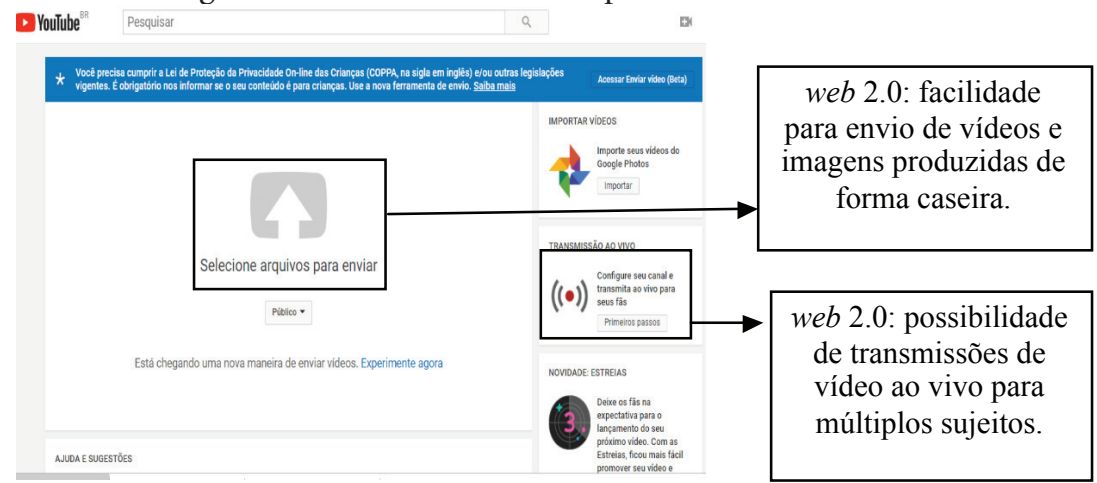

Fonte: Youtube. Disponível em: www.youtube.com.br; Acesso em: 27 mar. 2020.

Temos considerado os sistemas de distribuição da informação como tecnologias que oscilam entre o uso e desuso (aparelhos de rádio, televisão, telefone, celular, tablet etc.), mas os protocolos culturais estabelecidos no uso de tais tecnologias, por vezes, permanecem no tempo enquanto fenômenos culturais. A televisão não eliminou o rádio, o celular não eliminou os jogos de futebol no recreio da escola, as mídias digitais não eliminaram a televisão. Convergem enquanto práticas sociais, de forma híbrida, onde o jovem estu- 
dante ouve rádio pelo Spotify enquanto faz pesquisa para a escola em um site da internet e alterna, entre abas do seu navegador, vídeos do YouTube que podem incluir os gols do final de semana, do campeonato brasileiro de futebol, transmitidos pela TV no dia anterior (JENKINS, 2009).

Leite (2009) traz a reflexão da condição cultural de uma adolescência empoderada, que transita com facilidade nos ambientes virtuais, por vezes, ensinando e/ou assumindo a operação de compras, correspondência e outros fazeres na internet em suas famílias ou na escola. No entanto, Jenkins (2009, p. 364) acrescenta ao debate as hipóteses do engajamento ou alienação: (i) a participação no ciberespaço desperta o engajamento cívico ao envolver os sujeitos nas mais diversas associações, desde games a culinária, promovendo a liberdade de expressão e a cultura participativa; (ii) a distração de questões da vida real, pois, deslumbrados pelas liberdades individuais, tornam-se apenas consumidores das informações que se avolumam cada vez mais rapidamente, não participando dos debates que têm o potencial de transformar as instituições sociais.

Portanto, o convívio dos alunos nos espaços digitais não é garantia que constituam seus processos narrativos, pois é preciso que compreendam as linguagens com as quais convivem, o que demanda um processo de aprendizagem (FERNANDES, 2019). Neste contexto, consideramos que uma prática educativa dialógica se faz quando os estudantes são desafiados a se posicionarem enquanto seres do mundo e com o mundo, pois promove uma aprendizagem que os auxilia a perceberem-se sujeitos não só no decorrer do processo de construção de conhecimento, como também no mundo em que vivem, na constituição de suas narrativas e nos espaços que frequentam e se informam - sejam eles físicos ou no ciberespaço (FREIRE, 1987).

Com o advento da cibercultura, os lugares de aprendizado ultrapassam os muros da escola; basta uma ferramenta tecnológica de acesso (FERNANDES, 2019). No entanto, apesar das bibliotecas digitalizadas e diversidade de documentários acessíveis a um clique, não há garantia de que esses conteúdos sejam buscados e acessados pelos discentes (LEITE, 2009), pois os jovens alunos podem ser "mais propensos a obter informações e notícias através de programas humorísticos e blogs" (JENKINS, 2009, p. 364).

A análise do fenômeno da expansão da cibercultura e das mídias digitais como oportunidade de promover a diversidade e capacitar a democracia não pode igno- 
rar como estamos distantes desse objetivo, ao permanecermos "atentos às dimensões éticas pelas quais estamos gerando conhecimento" (JENKINS, 2009, p. 369).

Ante os dados globais sobre a expansão do uso do YouTube, a presente pesquisa investigou o uso das mídias digitais em duas turmas do $6^{\circ}$ ano de escolaridade do Colégio Municipal Elza Ibrahim, na cidade de Macaé, Rio de Janeiro. Os estudantes elaboraram uma produção textual com o tema Minha relação com a tecnologia. A proposta foi escrever livremente sobre o uso da internet e os aparelhos que eles ou a família possuem e utilizam para acesso ao ciberespaço.

A pesquisa alcançou cinquenta e seis alunos, na qual cerca de setenta e um por cento destes possuem aparelhos celulares, oitenta por cento possuem computadores em suas casas e cerca de cinco por cento dos estudantes não possuem acesso ao ciberespaço diariamente (Tabela 1). Ainda que alguns alunos não sejam usuários diretos de eletrônicos, considera-se que estes dialogam com os discursos da cultura do ciberespaço e das mídias digitais (LEITE, 2009), pois a cultura é uma produção coletiva (FERNANDES, 2019).

Tabela 1 - Amostra de uso de internet pelos estudantes

\begin{tabular}{ccc}
\hline Usos de mídias digitais & Quantidade & $(\%)$ \\
\hline Possui celular próprio & 40 & 71,4 \\
Domicílio possui computador & 45 & 80,3 \\
Utiliza a internet diariamente & 53 & 94,6 \\
Acessa YouTube diariamente & 52 & 92,8 \\
Possui conta no Facebook & 37 & 66,0 \\
Joga on-line & 42 & 75,0 \\
Amostragem total & 56 & 100 \\
\hline
\end{tabular}

Fonte: Autor, 2020.

A análise das produções textuais demonstrou que cerca de noventa e quatro por cento dos alunos navegam diariamente na internet (Gráfico 1), sendo o YouTube a rede social mais acessada, diariamente manuseado por noventa e dois por cento dos alunos que utilizam a internet (Gráfico 2). Dois estudantes afirmaram possuir um canal no YouTube no qual postam conteúdo por eles produzido, além de compartilhar vídeos que gostaram. 


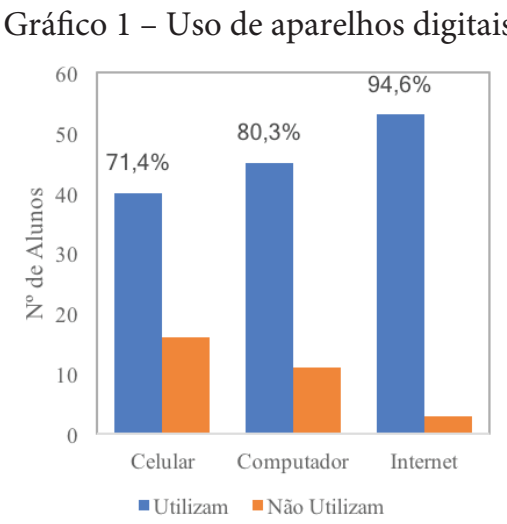

Fonte: Autor, 2020.

Gráfico 2 - Uso da internet.

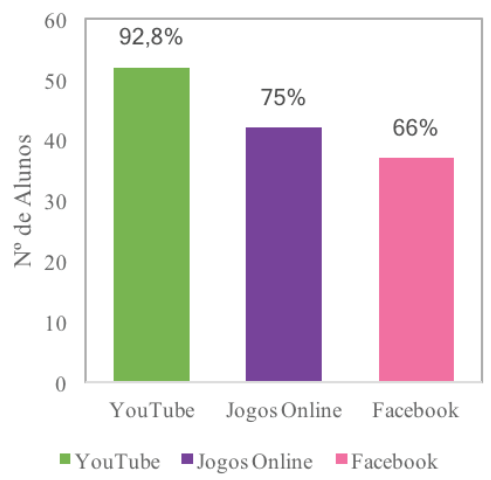

Fonte: Autor, 2020.

A escola locus da investigação não possui recursos de tecnologia digital para atendimento dos estudantes. Porém, este texto não se baseia nos sistemas de distribuição ou seus usos no ambiente escolar, mas no ensino-aprendizagem em História de jovens que, independente da oferta dos aparelhos tecnológicos pelo colégio, têm acesso e participam de ambientes virtuais.

Pautamos o ensino e a aprendizagem, no contexto das novas mídias, na valorização da busca, do estímulo e da reflexão, ao direcionarmos o olhar de forma plural: para o "objeto" de interesse e para nós mesmos, percebendo-nos, enquanto professores, como constituidores de um saber que é práxis, sujeitos 
que transformam-se ao agir sobre o mundo (SANTOS; WEBER, 2014). Práxis enquanto reflexão, ação e criação, no qual o professor se abstém de ocupar o lugar de narrador a jovens-objetos ouvintes, ao promover o narrar juntos, para que o aprendizado em História ocorra em diálogo às formas de ler, escrever e compreender o mundo dos estudantes (FREIRE, 1987).

Ao considerarmos que ler e escrever são construções sociais ressignificadas a cada época, a convergência das mídias e a cibercultura não podem ser ignoradas por nós professores em nossas práticas pedagógicas (MADDALENA; ROSSINI; SANTOS, 2018, p.107). Mesmo que as instituições escolares não ofereçam o suporte tecnológico, o professor de História pode considerar que os estudantes convivem em seu dia a dia com as mídias digitais.

Novas e antigas tecnologias interagem de forma cada vez mais complexa com transformações tecnológicas, mercadológicas, culturais e sociais onde antigas e novas práticas culturais se cruzam (JENKINS, 2009), nas quais as narrativas fragmentadas do YouTube convivem com as histórias contadas pelos pais e avós dos alunos. Sujeitos que têm em sua identidade diferentes referenciais, na qual ser leitor assume uma forma híbrida - ler, ouvir e ver - e possuem novos modos de perceber o tempo pelas aceleradas mudanças audiovisuais e informacionais (FERNANDES, 2019).

Na prática em sala de aula, ao incorporar a experiência histórica do conteúdo abordado ao espaço de experiência dos estudantes, operamos com a "contemporaneidade do não contemporâneo, na espessura temporal do 'espaço de experiência' e no presente do passado incorporado" (DOSSE, 2012, p. 6). Pois atuar sobre os passados presentes, que na experiência "fundem tanto a elaboração racional quanto as formas inconscientes de comportamento, que não estão mais, ou que não precisam estar mais presentes no conhecimento" (KOSELLECK, 2006, p. 309), visa promover que os estudantes abordem "a historicidade de suas determinações socioculturais, fundamento de uma compreensão de si mesmos como agentes históricos e de suas identidades como construções do tempo histórico." (PEREIRA; SEFFNER, 2008, p. 119).

A premissa de que as distâncias geográficas são encurtadas pela interação entre o físico e o digital (MADDALENA; ROSSINI; SANTOS, 2018) abre possibilidades metodológicas, pois, na falta de recursos para atividades externas, há possibilidade de visitar patrimônios, conhecer museus e percorrer roteiros pelo ciberespaço. Por meio da ferramenta Google Earth, ${ }^{5}$ por exemplo, podemos 
utilizar imagens de satélite para "visitar" locais e espaços que de outra forma, por motivos logísticos, os estudantes não explorariam. No YouTube, há possibilidade de assistir narrativas não-hegemônicas produzidas por movimentos sociais, onde os sujeitos participantes usam a própria voz para contar suas experiências.

Não defendemos que o virtual substitua a visitação física ou que cessem as lutas por melhorias de condições estruturais nas unidades escolares, e sim alternativas às necessidades da prática de ensino-aprendizagem no tempo presente. O que pode ocorrer de forma concomitante à busca de melhores condições para a instituição escolar, mas cientes que o aprendizado ocorre no presente, que o aluno está no instante em que ocupa a sala de aula na expectativa de ouvir e participar das atividades propostas pelos professores. Ter o cuidado metodológico de não esperar que inovações tecnológicas ou o futuro por si só resolverá as mazelas estruturais da educação, sempre no aguardo de um tempo melhor, sem agirmos sobre ele.

Ademais, consideramos que uma abordagem que não se restrinja aos formatos referenciados na infância dos professores tem a potência de evitar o fechamento da possibilidade de os estudantes elaborarem narrativas imaginárias que dialoguem com seus próprios contextos sociais no decorrer do processo de aprendizagem. Pois as formas de produção cultural são modificadas pelos espaços de cultura ao transformar as experiências dos sujeitos - fenômeno que se reflete nas escolhas das narrativas que os alunos gostam de ler e construir, no qual as emoções também se manifestam, visto ser um dos vínculos entre a imaginação e a realidade, o emocional. (FERNANDES, 2019).

Nesta perspectiva, consideramos que o ensino de História tem o potencial de promover a apropriação de experiências passadas, visto que é com base na variedade da experiência acumulada pela humanidade que ocorre a construção da narrativa que faz uso da imaginação (FERNANDES, 2019). Dessa forma, evitando a temporalidade moderna justificadora de uma hierarquização de culturas - que resulta na aceitação e reprodução do status quo (KOSELLECK, 2006) -, a hipertrofia do presente (HARTOG, 2013) ou uma relação temporal na qual o horizonte de expectativas estaria no pós-vida, sendo o plano terreno refém da tradição e conservação dos costumes.

A aula de História na qual o estudante é protagonista ao tecer problematizações acerca das narrativas contadas pelo professor (sejam elas fábulas, len- 
das ou processos históricos) e ao construir as próprias narrativas com uso de mídias digitais - em diálogo às suas práticas culturais, vivências e saberes -, oportuniza avaliar a aprendizagem em História não nas formas de responder a complexidade do conteúdo curricular, mas de compreender tal complexidade, interrogando sobre as visões de mundo dadas pelas experiências pessoais dos educandos, constituindo-os sujeitos do processo de aprendizagem (SANTOS; WEBER, 2014).

\section{CONSIDERAÇÕES FINAIS}

Com a crescente pressão dos tempos do mercado nas políticas públicas da educação e as vivências dos estudantes marcadas pelo fenômeno da expansão do ciberespaço, temos considerado que se torna ainda mais relevante para os jovens estudantes o aprendizado de conceitos e outras experiências históricas, além da competência de localizar-se no tempo como sujeitos históricos. Se a cibercultura privilegia a noção de simultaneidade e contribui com o fenômeno do presentismo - no qual o presente torna-se perpétuo ao esvaziar o passado e ser o único horizonte possível enquanto corrida pela constante atualização -, as mídias digitais junto ao ciberespaço, mediadas pelo professor, são potenciais ferramentas de ensino-aprendizagem em História.

O desenvolvimento de atividades com a contação e construção de narrativas - uma prática tão antiga quanto a nossa história, enquanto humanos pode de forma híbrida ser operada junto ao uso de mídias digitais - seja em jogos, vídeos, construção de avatares ou animações - com uso da imaginação (CUESTA, 2015). Nesse fazer, a aprendizagem ocorre no espaço da brincadeira, com a possibilidade de selecionar, junto com os alunos, aplicativos em que não há uma busca por vencer e sim cooperar com o outro, na qual a principal motivação seja a de participar e, em sua dinâmica, desenvolva ações a partir do que consideram a vida real, referenciada nas suas vivências e no conteúdo de História (VYGOTSKY, 2008).

A produção narrativa insere o discurso dos alunos no espaço e no tempo, além de possuir importante papel na significação do tempo histórico (SANTOS, 2015). Portanto, a aprendizagem em História que seja significativa para o estudante transcende ao conteúdo curricular, sem abrir mão dele, pois dialoga com as experiências e as práticas culturais dos discentes. Ao dialogarmos 
com as vivências dos estudantes, legitimarmos na sala de aula - valorizando suas habilidades no uso mídias digitais e navegação pelo ciberespaço - e as operarmos sob as bases conceituais e metodológicas da aula de História, construídas pelo professor-autor junto aos estudantes, percebemos a potência para construção do conhecimento histórico escolar.

\section{REFERÊNCIAS}

BARROS, José D’Assunção. Teoria da História: princípios e conceitos fundamentais. Petrópolis: Vozes, 2011.

BENJAMIN, Walter. O Narrador: considerações sobre a obra de Nikolai Leskov. In: BENJAMIN, Walter. Magia e Técnica, Arte e Política. Obras escolhidas. São Paulo: Brasiliense, 2012. Edição Kindle.

BLOCH, Marc. Apologia da História ou o ofício do historiador. Rio de Janeiro: Zahar, 2002.

BRINCO, Naicon de Souza. Ensino de História na Cibercultura: narrativas sobre a ocupação do território e cidadania a partir da experiência histórica romana e o Tempo Presente. Dissertação (Mestrado Profissional em Rede Nacional PROFHISTORIA) - Faculdade de Formação de Professores, Universidade do Estado do Rio de Janeiro, São Gonçalo, 2020. 171f.

CAIMI, Flávia Eloisa; OLIVEIRA, Sandra Regina Ferreira de. Os jovens e a aula de história: entre tensões, expectativas e possibilidades. Revista Educação em Questão, Rio Grande do Norte, v. 44, n. 30, set./ dez, p. 88-109, 2012.

CANDAU, Vera. Memória(s), diálogos e buscas: aprendendo e ensinando didática. In: CANDAU, Vera (Org.). Didática, questões contemporâneas. Rio de Janeiro: Forma e Ação, 2009.

CUESTA, Virginia. Enseñanza de la História y enfoque narrativo. Revista História Hoje, v. 4, n. 8, p. 152-173, 2015.

DOSSE, François. História do tempo presente e historiografia. Revista Tempo e Argumento. Revista do Programa de Pós-graduação em História, Florianópolis, v. 4, n. 1, p. 5-22, jan./jun. 2012

FERNANDES, Adriana Hoffmann. Narrativa de crianças na sociedade da imagem. Curitiba: Appris, 2019.

FERREIRA, Rodrigo de Almeida. Qual a relação entre a história púbica e o ensino de História? In: MAUAD, Ana Maria et al. (org.). Que história pública queremos? São Paulo: Letra e Voz, 2018.

FREITAS, Itamar. Narrativa Histórica. In: FERREIRA, Marieta de Moraes; OLIVEI- 
RA, Margarida Maria D. (org.). Dicionário do ensino de História. Rio de Janeiro: FGV, 2019.

FREIRE, Paulo. Pedagogia do oprimido. Rio de Janeiro: Paz e Terra, 1987.

HARTOG. Regimes de historicidade: presentismo e experiências do tempo. Belo Horizonte: Autêntica, 2013.

JENKINS, Henry. Cultura de convergência. São Paulo: Aleph, 2009.

KALLÁS, Ana Lima. Usos públicos da história: origens do debate e desdobramentos no ensino de História. Revista História Hoje, v. 6, n. 12, p. 130-157, 2017.

KOSELLECK, Reinhart. Futuro passado. Rio de Janeiro: PUC Rio/Contratempo, 2006.

LEITE, Miriam Soares. Entre a bola e o MP3 - novas tecnologias e diálogo intercultural no cotidiano escolar adolescente. In: CANDAU, Vera (org.). Didática, questões contemporâneas. Rio de Janeiro: Forma e Ação, 2009.

LUCCHESI, Anita. A história sem fio: questões para o historiador da Era Google. In: $X V$ Encontro Regional de História - ANPUH-Rio, p. 1-9. Ofício do Historiador: Ensino e Pesquisa. São Gonçalo: ANPUH-RIO, 2012.

LUCCHESI, Anita. Histórias no ciberespaço: viagens sem mapas, sem referências e sem paradeiros no território incógnito da Web. Cadernos do Tempo Presente, n. 6, p. 01-17, 2014.

MADDALENA, Tania Lucía; ROSSINI, Tatiana Stofella Sodré; SANTOS, Edméa. Diário hipertextual online de pesquisa: uma experiência com o aplicativo Evernote. In: EDMÉA, Santos; CAPUTO, Stela Guedes (org.). Diário de pesquisa na cibercultura: narrativas multirreferenciais com os cotidianos. Rio de Janeiro: Omodê, 2018.

MARRACH, Sônia. Outras histórias da educação: do Iluminismo à Indústria Cultural (1823-2005). São Paulo: UNESP, 2009.

MATTOS, Ilmar R. Mas não somente assim; leitores, autores, aulas como texto e o ensino-aprendizagem de História. Revista Tempo. Departamento de História da UFF. Rio de Janeiro, v. 11, n. 21, p. 5-16, jul. 2006.

MIRANDA, Sonia Regina. Aprender e ensinar o tempo histórico em tempos de incertezas: reflexões e desafios para o professor de história. In: GONÇALVES, M. et al. (org.). Qual o valor da história hoje? Rio de Janeiro: Editora FGV, 2012.

PEREIRA, Nilton Mullet; SEFFNER, Fernando. O que pode o ensino de história? Sobre o uso de fontes na sala de aula. Anos 90. Porto Alegre, v. 15, n. 28, dez, p. 113128, 2008.

RICOEUR, Paul. Tempo e narrativa. Tradução Constança Marcondes Cesar. Tomo I. Papirus: São Paulo, 1994.

SANTOS, Edméa; WEBER, Aline. Diários online, cibercultura e pesquisa-formação 
multirreferencial. In: SANTOS, Edméa (Org.). Diário online: dispositivo multirereferencial de pesquisa formação na cibercultura. Whitebooks: Santo Tirso, Portugal, 2014.

SANTOS, Maria Aparecida Lima. Práticas da escrita escolar no ensino de História: indício de significação do tempo em manuscritos escolares. Revista Histórica Hoje, v. 4, n. 8, p. 104-109, 2015.

TURIN, Rodrigo. Entre o passado disciplinar e os passados práticos: figurações do historiador na crise das humanidades. Tempo, v. 24, n. 2, p. 186-205, 2018.

VYGOTSKY, Lev Semenovich et al. Pensamento e linguagem. São Paulo: Martins Fontes, 2008.

\section{NOTAS}

${ }^{1}$ Trata-se da dissertação de mestrado intitulada Ensino de História na Cibercultura: narrativas sobre a ocupação do território e cidadania a partir da experiência histórica romana e o Tempo Presente, de Naicon de Souza Brinco, sob a supervisão da Prof. ${ }^{a}$ Dra. Maria Aparecida da Silva Cabral, no Programa de Pós-graduação em Ensino de História - Mestrado Profissional - Profhistória/UERJ.

${ }^{2}$ Dados disponíveis em: https://www.youtube.com/intl/pt-BR/yt/about/press/. Acesso em: 10 mar. 2019.

3 "Linguagem escrita não-linear, composta por fragmentos de textos que podem ser acessados e sequenciados conforme o interesse e a necessidade do sujeito. Os conteúdos são acessados e conectados a partir de nós da conexão (links), fazendo parte da construção do hipertexto" (MADDALENA; ROSSINI; SANTOS, 2018).

${ }^{4}$ Lucchesi (2012) cita a Era Google em seu artigo A História sem fio: questões para o historiador da Era Google apresentado no XV Encontro de História Regional da Anpuh-Rio, em 2012, tendo como referência a relação da Internet com a História, discutida por Carlo Ginzburg Durant durante o evento Fronteiras do Pensamento.

${ }^{5}$ Disponível em: https://www.google.com.br/intl/pt-BR/earth>. Acesso em: 30 mar. 2020.

Artigo recebido em 31 de agosto de 2020. Aprovado em 13 de outubro de 2020. 